\title{
Assessing Knowledge about the Dangers of Alcohol Consumption: A Cross-sectional Descriptive Study, among Makerere University Undergraduate Students
}

\author{
Emyedu Andrew ${ }^{1}$, P. Babua ${ }^{1}$, J. Nabukalu ${ }^{1}$, Denis Mugarura ${ }^{1}$, C. Ochwo ${ }^{1}$, T. I. Nahereza ${ }^{1}$, I. Ssinabulya ${ }^{2}$ and H. \\ Wabinga $^{3}$ \\ 1. Department of Medicine, College of Health Sciences, Makerere University, Kampala P.O. Box 7062, Uganda \\ 2. Department of Pathology, College of Health Sciences, Makerere University, Kampala P.O. Box 7062, Uganda
}

\begin{abstract}
Consumption of alcohol and other alcoholic beverages is widespread in Uganda and it is the highest per capita consumer of alcohol in Africa. Many households are involved in informal alcohol production for income purposes, resulting in alcohol being easily available. Alcohol is consumed mostly by adults and young adults, waragi (a local brew) being high on the menu. There is a high prevalence of alcohol consumption at Makerere University so in our study we set out to assess the knowledge about dangers of alcohol consumption among these students. It was a cross-sectional descriptive study. The target population was undergraduate students of Makerere University. Data were collected using self-administered questionnaires and focus group discussions. We interviewed 435 University students, 236 (54.3\%) males and 199 (45.7\%) females. Median age was 21 years, similar across gender. There were more participants from year one to three compared to years four and five. Majority of the students were consuming alcohol 242 (55.6\%), 49 (11.3\%) had stopped and 144 (33.1\%) had never consumed alcohol. A higher proportion of males consumed alcohol compared to females; $60.2 \%$ and $50.2 \%$ respectively. Some reasons given for alcohol consumption were: peer pressure, coping with stressful situations, celebration and the need for adventure. The students were knowledgeable about the dangers of alcohol consumption like liver disease, violence, mental illness, cancer, diabetes mellitus, financial loss and death. Despite the vast knowledge about the dangers of alcohol consumption, some students were reluctant to stop consuming alcohol, so fighting this habit in this population is important. Parents and students need to be mindful of where to reside so as to avoid bad company. Some of the students who stopped consuming alcohol attributed it to concern from a relative, friend or health worker, so involving the entire public could go a long way in the fight against alcohol abuse as well as strict regulation of physical availability of alcohol on the university campus.
\end{abstract}

Key words: Alcohol consumption, Makerere University students, dangers of alcohol consumption.

$\begin{array}{ll}\text { Abbreviations } & \\ \text { CAGE } & \text { Cut down, anger, guilt, Eye opener } \\ \text { COA } & \text { Children of alcoholics } \\ \text { IRB } & \text { Institutional review board } \\ \text { FGDs } & \text { Focus group discussions }\end{array}$

\section{Background}

According to the latest global report on alcohol use, Ugandans are the highest per capita consumers of alcohol in Africa [1], largely thanks to a rampant trade in locally made alcohol from bananas at household

Corresponding author: Emyedu Andrew, MBChB, research field: public health research. level [2]. Uganda also has a large number of abstainers, which indicates that those people who do drink tend to consume substantial amounts of alcohol [1]. Young people in Uganda seem to follow a similar pattern of alcohol consumption to that of the general population and many young people are experiencing the consequences of drinking too much, at too early an age $[3,4]$.

While the exact cause of alcoholism is unknown, research has shown increasing evidence that susceptibility to this habit may be inherited and the risk of developing this medical condition rises significantly in families with relatives who are 
dependent on alcohol [5]. COAs (children of alcoholics) are more likely to begin drinking at a young age and to progress to drinking problems more quickly [6, 7]. Young people model their own behavior according to their parents' patterns of consumption, contexts of use, attitudes regarding use, and use expectancies $[5,8]$.

All drugs affect a "reward mechanism" in the brain and if a person feels good each time they use a drug, it tends to make them want to use it again $[2,8]$. Just like other drugs, alcohol causes a sensation of euphoria ("getting high") and if used regularly, the body tends to require increasing amounts of the substance to achieve the same effect. This is called tolerance and it may contribute to the development of drug or alcohol dependence and addiction $[2,9,10]$.

Historically, doctors have promoted alcohol for its perceived health benefits and most recently for protection against coronary heart disease [10]. There is evidence of cardiovascular benefits from having 1 to 2 drinks per day; however, the health benefits from moderate intake of alcohol are controversial and it should not be used in the place of safer and proven traditional methods like exercise and proper nutrition $[10,11]$.

Alcohol accounts for $4 \%$ of the global disease burden each year [12]. It is highly linked with the etiology of cancer [13], gastritis, stomach ulcers, mental illness [4, 2], stroke [14], dementia and cardiac diseases [12]. It is also toxic to liver cells [11] and many heavy drinkers develop cirrhosis [13]. However, it is hard to predict which drinks will develop cirrhosis. Some people who drink huge amounts never get it, while some who don't drink very much do get it. Women seem to be especially vulnerable [12].

Research has also shown that alcohol depresses the central nervous system including the part that restrains and inhibits our behavior [3]. Thus, following a binge of alcohol, people are more likely to engage in risky sexual behavior $[3,15]$ thus increasing the risk of sexually transmitted diseases like HIV/AIDS and this has retarded the gains made in HIV prevention in Uganda [2, 3, 15]. This study was used to assess knowledge about the dangers of alcohol consumption among undergraduate students at Makerere University.

\section{Methods}

\subsection{Study Design}

The study was a cross-sectional descriptive study.

\subsection{Study Setting}

It was carried out at Makerere University, the oldest tertiary institution in Uganda. It has both undergraduate and post graduate students. The study participants were undergraduate students and these make up a population of approximately 30,000 students.

\subsection{Study Participants}

The study was conducted amongst undergraduate students offering various courses, in different places of residence (halls, hostels and those who come from home) and in different years of study ranging from first to fifth year. A sample size of 422 was determined using the Keish and Leslie formula. A random sampling method was used while giving out self-administered questionnaires to the students. Four focus group discussions were held at the halls of residence, each comprising of 8-12 students offering different courses in different years of study. The questionnaires were prepared by reviewing relevant literature like the CAGE and AUDIT system. Pre-test was done using $10 \%$ of the subjects which showed that the questions captured the objectives of the study and a student needed about 25 minutes to fill the questionnaire.

\subsection{Data Analysis}

The collected data were cleaned, coded, entered 


\section{Assessing Knowledge about the Dangers of Alcohol Consumption: A Cross-sectional Descriptive Study, 123 among Makerere University Undergraduate Students}

into EPIDATA Version 3.1 software and transferred and analyzed using SPSS software package version 16.0.

\subsection{Ethical Considerations}

The study was reviewed and approved by the Ethical Review Board, School of Medicine at Makerere University. The purpose, benefits and risks of the study were explained to the participants who signed a consent form attached to the questionnaire. Consent to record focus group discussions was given verbally.

\section{Results}

We interviewed 435 University students, 236 (54.3\%) males and 199 (45.7\%) females (Table 1). Median age IQR (inter quartile range) was 21 (20-22) years, similar across gender, 21 (20-23) and 21 (20-22) for males and females respectively. There were more participants from year one to three compared to years four and five. Majority of the students were consuming alcohol 242 (55.6\%), 49 (11.3\%) had stopped and 144 (33.1\%) had never consumed alcohol 144 (33.1\%). A higher proportion of males consumed alcohol compared to females; $60.2 \%$ and $50.2 \%$ respectively (Table 2).

Some of the reasons given for consuming alcohol were: peer influence, addiction, the need to boost ones' confidence, celebration, love for the good feeling (euphoria) that comes with alcohol consumption, while others drink because it is healthy when taken in small quantities (Table 3 ).

One of the students at the focus group discussions attributed alcoholism to family influence and he adopted a phrase commonly used by his brother, “Alcohol doesn't solve a man's problem but neither does milk."

Some of the students used to take alcohol but stopped, 49 (11.3\%) and the reasons given for quitting include; health reasons 18 (34.6\%), advice from friends $11(21.2 \%)$ and change of religion 14 (26.9\%).

From the focus group discussions, the reasons given for quitting included: decline in academic performance, near death experiences after taking alcohol like accidents, influence from partners and some people just outgrow the stage. "Some realize they are not gaining from the alcohol. You take alcohol to forget your problems and the next day you wake up with the same problems plus a hangover".

According to the CAGE score an alcoholic is one who has a score of 2 and above out of 4 . So basing on that, $50(11.4 \%)$ of Makerere university students were alcoholics (Table 4).

According to the students some of the dangers of alcohol consumption were: financial loss, family wrangles, domestic violence, mental illness, loss of respect, sexual recklessness (leading to sexually transmitted diseases and unwanted pregnancies).

Focus group discussions generated other dangers including: decline in academic performance, poor health like, diabetes mellitus, cancers, impotence, liver disease and death.

"The Nkozi story where people die along the Masaka high way due to drunk driving and in a split second someone dies just due to the excitement."

Table 1 Gender distribution across year of study for study participants .

\begin{tabular}{llll}
\hline Year of study & Male n (\%) & Female $\mathrm{n}(\%)$ & Total n (\%) \\
\hline Year one & 46 & 59 & $105(24.1)$ \\
Year two & 89 & 57 & $146(33.6)$ \\
Year three & 54 & 61 & $115(26.4)$ \\
Year four & 26 & 19 & $45(10.3)$ \\
Year five & 21 & 3 & $24(5.5)$ \\
\hline
\end{tabular}


124 Assessing Knowledge about the Dangers of Alcohol Consumption: A Cross-sectional Descriptive Study, among Makerere University Undergraduate Students

Table 2 Age, year of study, residence and gender distribution versus alcohol consumption among study participants.

\begin{tabular}{llll}
\hline & Consumes alcohol $(\mathrm{n}=242)$ & Stopped alcohol consumption $(\mathrm{n}=49)$ & Never consumed alcohol $(\mathrm{n}=144)$ \\
\hline $\begin{array}{l}\text { Median age (IQR) } \\
\text { Year of study }\end{array}$ & $20(19-22)$ & $21(20-22)$ & $21(20-23)$ \\
Year one, $\mathrm{n}(\%)$ & $48(45.7)$ & $10(9.5)$ & $47(44.8)$ \\
Year two, $\mathrm{n}(\%)$ & $88(60.3)$ & $15(10.3)$ & $43(29.4)$ \\
Year three, $\mathrm{n}(\%)$ & $60(52.2)$ & $18(15.6)$ & $37(32.2)$ \\
Year four, $\mathrm{n}(\%)$ & $29(64.4)$ & $5(11.1)$ & $11(24.4)$ \\
Year five, $\mathrm{n}(\%)$ & $17(70.8)$ & $1(4.2)$ & $6(25.0)$ \\
Residence & & & \\
Hall, $\mathrm{n}(\%)$ & $138(53.1)$ & $30(11.5)$ & $92(35.4)$ \\
Hostel, $\mathrm{n}(\%)$ & $81(61.8)$ & $13(9.9)$ & $37(28.2)$ \\
Home, $\mathrm{n}(\%)$ & $23(52.3)$ & $6(13.6)$ & $15(34.1)$ \\
Gender & & & $71(30.1)$ \\
Male, $\mathrm{n}(\%)$ & $142(60.2)$ & $23(9.7)$ & $73(36.7)$ \\
Female, $\mathrm{n}(\%)$ & $100(50.2)$ & $26(13.1)$ &
\end{tabular}

Table 3 Various reasons why some of the students stopped consuming alcohol.

\begin{tabular}{lll}
\hline Reason & No. of students & Percentage \\
\hline Health & 18 & 34.6 \\
Advice FROM friends & 11 & 21.2 \\
Change in religion & 14 & 26.9 \\
Other reasons & 9 & 17.3 \\
Total & 52 & 100 \\
\hline
\end{tabular}

Table 4 The cage categorization among students who consume alcohol.

\begin{tabular}{ll}
\hline Cage score & $\mathrm{N}(\%)$ \\
\hline 0 & $121(49.8)$ \\
1 & $72(29.6)$ \\
2 & $21(8.6)$ \\
3 & $17(7.0)$ \\
4 & $12(4.9)$ \\
\hline
\end{tabular}

Table 5 Some of the dangers of alcohol consumption.

\begin{tabular}{lll}
\hline Alcohol effects & Frequency & Percentage \\
\hline Financial loss & 366 & 84.14 \\
Decline in academic performance & 263 & 60.46 \\
Mental illness & 238 & 54.71 \\
Liver disease & 312 & 71.72 \\
Sexual recklessness & 314 & 72.18 \\
Road traffic accidents & 354 & 81.38 \\
Other reasons & 15 & 3.45 \\
\hline
\end{tabular}

\section{Discussion}

Our study showed a high prevalence of alcohol consumption, $55.6 \%$ amongst undergraduate students of Makerere University. This was lower than the figures found in a similar study by Kabaireho at the same university $(78 \%)$ in 1989 [4]. The decline in alcohol consumption over the years could be attributed to the increased level of awareness about the dangers of alcohol consumption from school, media and the internet $[2,4]$. However, alcohol consumption at Makerere University is still high and this could be 
accounted for, in part, the easy accessibility and affordability of alcohol [4]. The university is surrounded by an array of about 500 bars in the surrounding suburbs like Wandegeya and Kikoni which sell both local and conventional alcoholic beverages. Alcohol is also sold at the canteens within the hostels and halls of residence in affordable forms like sachets along with the bottled forms [4]. Affordability of alcohol is strongly linked to alcohol abuse and increase in money available to adolescents for their leisure activities further accentuates their drinking problems [16].

Majority of students from the FGDs confessed to have had their first drink at parties held by students (drink-ups) where there is binge drinking and alcohol is served to everyone, while for others it was at the bazaars (welcome parties for first year students). These parties are usually sponsored by brewery companies and alcohol is given to students as freebies and also discounted to lower prices making it more affordable with an intention of initiating the new students, this is the most troubling form of advertising by the brewery companies. [4, 16].

We found a positive correlation between alcohol consumption and having a close relative who consumed alcohol. This was in line with the finding that alcohol problems tend to aggregate in families [7]. COAs are between 4 to 10 times more likely to become alcoholics themselves than those who have no close relatives who are alcoholics [8]. This family transmission can reflect genetics or modeling behavior, the structure and environment of the family unit, as well as parent-child relationship attributes like: parenting style, attachment and bonding, nurturance, abuse or neglect, conflict, discipline, and monitoring [7].

Some students started consuming alcohol due to peer influence ("I drink because when we go out, all my friends do."). Due to the innate need to belong, adolescents are often willing to conform to their peers' behaviors in order to be accepted [4, 17].
Conformity may create problems like when peers influence each other to participate in deviant activities like alcohol and substance abuse [17].

Students also cited the need to cope with stressful situations as a reason for drinking. Similarly, in a study carried out among university students in France, negative affect predicted heavy drinking, however, young adults are more likely to drink for "positive" or celebratory reasons than to drink to cope with negative feelings $[2,18,19]$.

From our study, more boys, 142 (60.2\%) consumed alcohol than girls, 100 (50.2\%). This was in line with several studies which showed that boys are more likely to consume alcohol than girls $[2,4,14]$. This can be attributed to the fact that selling of alcoholic beverages in the canteens is prohibited in the girls' residences unlike in the boys' residences [4].

Some of the students used to take alcohol but stopped, 49 (11.3\%). One of the reasons given for this was change in religion, $49(11.3 \%)$ mostly to Islam while others became Pentecostals and in both religions, alcohol is prohibited $[1,10]$. One of the students "who found God" quoted Isaiah 5.22 "Woe unto those who are heroes of the wine bottle and champions at mixing this strong drink." And he said it is because of this verse that he stopped consuming alcohol. Others quit the habit due to the increase in academic load, negative experiences after drinking and reduced excitement due to drinking. One study that followed college students over 3 years found a decline in positive expectancies after consuming alcohol [19], while others simply matured out of the habit [18]. However, people with a family history of alcoholism are less likely than those with no family history to mature out of heavy drinking [19].

Students knew some dangers of alcohol consumption and some linked alcohol consumption to aggression. A bar violence study, conducted in New York found that the more drinks one had consumed, the more violent they became and the more severe the injuries to themselves as well as to the other person 
involved [20]. In a survey of 5,109 women of reproductive age in Rakia (a district in Uganda), it was found that $52 \%$ of women who reported recent domestic violence had partners who had consumed alcohol before the incident [21].

In a study among Mbarara University students, alcohol consumption was found to be associated with having multiple sexual partners and inconsistent condom use with new partners among students who often used alcohol [3]. Sexual recklessness, 314 (72.18\%) following binge drinking was attributed to its ability to depress one's cognitive functioning $[2,22]$. Students who take alcohol are more likely to be involved in a road traffic accident, 354 $(81.38 \%)$, which can result in death or permanent disability .

\section{Conclusions}

The alcohol consumption in Makerere University is still high and this could be attributed to: the band wagon effect since most students have close relatives or friends who take alcohol, lack of clear understanding about the dangers of alcoholism both short term and long term, and keeping away from religion. Therefore if alcoholism is to be reduced among Makerere University students, these issues have to be addressed right from when the students join the university. Parents and students need to be mindful of where to reside to avoid bad company. Strict regulation of physical alcohol availability and advertising bans could help fight this habit.

\section{Acknowledgments}

Research reported in this publication was supported by MESAU MEPI under Award Number 1R24TW008886. The authors would like to thank MESAU MEPI for the opportunity provided to us to carry out the above research. The content is solely the responsibility of the authors and does not necessarily represent the official views of the National Institutes of Health.

\section{Authors' Contributions}

A. E. conceptualized the study, guided the analyses and drafted sections of the manuscript. P. B., D. M., and B. K. led the data collection, provided contextual information conducted the literature review and drafted sections of the manuscript. N. T. I., and C. O. participated in data collection, interpreted and reviewed analyses. All authors reviewed multiple versions of the manuscript and read and approved the final manuscript. I. S., and H. W. were the supervisors and provided guidance in developing the proposal, data collection and analysis as well as manuscript development.

\section{Competing Interests}

The authors declare that they have no competing interests.

\section{References}

[1] Fleischmann, A., Fuhr, D., Poznyak, V., and Rekve, D. 2011. World Health Organization Global Status Report on Alcohol and Health.

[2] Naamara, W., and Muhwezi, W. W. 2014. "Factors Associated with Alcohol Dependence among Adult Male Clients in Butabika Hospital, Uganda." Journal of Social Work Practice in the Addictions 14 (3): 322-6.

[3] Choudhry, V., Agardh, A., Stafström, M., and Östergren, P. O. 2014. "Patterns of Alcohol Consumption and Risky Sexual Behavior: A Cross-Sectional Study among Ugandan University Students.” BMC Public Health 14 (1): 128.

[4] Grant, B. F., and Dawson, D. A. 1997. "Age at Onset of Alcohol Use and Its Association with DSM-IV Alcohol Abuse and Dependence: Results from the National Longitudinal Alcohol Epidemiologic Survey." Journal of Substance Abuse 9: 103-10.

[5] Caleekal, J. A., and Goodstadt, M. S. 1983. "Alcohol Use and Its Consequences among Canadian University Students." Canadian Journal of Higher Education 13 (2): 59-69.

[6] White, H. R., Johnson, V., and Buyske, S. 2000. "Parental Modeling and Parenting Behavior Effects on Offspring Alcohol and Cigarette Use: A Growth Curve Analysis." Journal of Substance Abuse 12 (3): 287-310.

[7] Swaim, R. C., Beauvais, F., Walker, R. D., and Silk, W. P. 2011. "The Effects of Parental Diagnosis and Changing Family Norms on Alcohol Use and Related Problems 
Assessing Knowledge about the Dangers of Alcohol Consumption: A Cross-sectional Descriptive Study, 127 among Makerere University Undergraduate Students

among Urban American Indian Adolescents." The American Journal on Addictions 20 (3): 212-9.

[8] Caan, W., and De Belleroche, J. 2002. Drink, Drugs and Dependence: From Science to Clinical Practice. Hove: Psychology Press.

[9] Ellickson, P. L., Tucker, J. S., and Klein, D. J. 2003. "Ten-Year Prospective Study of Public Health Problems Associated with Early Drinking." Pediatrics 111 (5): 949-55.

[10] Gobbens. R., Luijkx, K., Wijnee, M. T., and Schols, J. 2010. "Towards an Integral Conceptual Model of Frailty." The Journal of Nutrition, Health \& Aging 14 (3): 175-81.

[11] Rehm, J., Mathers, C., Popova. S., Thavorncharoensap, M., Teerawattananon, Y., and Patra, J. 2009. "Global Burden of Disease and Injury and Economic Cost Attributable to Alcohol Use and Alcohol-Use Disorders." The Lancet 373 (9682): 2223-33.

[12] Tuyns, A. J., Esteve, J., Raymond, L., Berrino, F., Benhamou, E., Blanchet, F., Boffetta, P., Crosignani, P., Moral, A. D., and Lehmann, W. 1988. "Cancer of the Larynx/Hypopharynx, Tobacco and Alcohol: Iarc International Case-Control Study in Turin and Varese (Italy), Zaragoza and Navarra (Spain), Geneva (Switzerland) and Calvados (France)." International Journal of Cancer 41 (4): 483-91.

[13] Caicoya, M., Rodriguez, T., Corrales, C., Cuello, R., and Lasheras, C. 1999. "Alcohol and Stroke: A Community Case-Control Study in Asturias, Spain." Journal of Clinical Epidemiology 52 (7): 677-84.

[14] Mbulaiteye, S., Ruberantwari, A., Nakiyingi, J., Carpenter, L., Kamali, A., and Whitworth, J. 2000. "Alcohol and HIV: A Study among Sexually Active Adults in Rural Southwest Uganda." International Journal of Epidemiology 29 (5): 911-5.
[15] Jernigan, D. 2013. "Why South Africa's Proposed Advertising Ban Matters." Addiction 108 (7):1183-1185.

[16] Newman, I. M. 1984. "Capturing the Energy of Peer Pressure: Insights from a Longitudinal Study of Adolescent Cigarette Smoking." Journal of School Health 54 (4): 146-8.

[17] Goldberg, J. H., Halpern, B. L., and Millstein, S. G. 2002. "Beyond Invulnerability: The Importance of Benefits in Adolescents' Decision to Drink Alcohol." Health Psychology 21 (5): 477.

[18] Tavolacci, M. P., Ladner, J., Grigioni, S., Richard, L., Villet, H., and Dechelotte, P. 2013. "Prevalence and Association of Perceived Stress, Substance Use and Behavioral Addictions: A Cross-Sectional Study among University Students in France, 2009-2011.” BMC Public Health 13 (1): 724.

[19] Leonard, K. E., Collins, R. L., and Quigley, B. M. 2003. "Alcohol Consumption and the Occurrence and Severity of Aggression: An Event-Based Analysis of Male to Male Barroom Violence." Aggressive Behavior 29 (4): 346-65.

[20] Koenig, M. A., Lutalo, T., Zhao, F., Nalugoda, F., Wabwire, M. F., Kiwanuka, N., Wagman, J., Serwadda, D., Wawer, M., and Gray, R. 2003. "Domestic Violence in Rural Uganda: Evidence from a Community-Based Study." Bulletin of the World Health Organization 81 (1): 53-60.

[21] Rehm, J., Room, R., Graham, K., Monteiro, M., Gmel, G., and Sempos, C. T. 2003. "The Relationship of Average Volume of Alcohol Consumption and Patterns of Drinking to Burden of Disease: An Overview." Addiction 98 (9): 1209-28.

[22] Borkenstein, R. F., Crowther, R., and Shumate, R. 1974. "The Role of the Drinking Driver in Traffic Accidents (The Grand Rapids Study)." Blutalkohol 11 (Suppl.): $1-131$. 